\title{
A hybrid approach to the study of CPFR implementation enablers
}

Panahifar, F., Byrne, P.J., Heavey, C.. 2015. A hybrid approach to the study of CPFR implementation enablers. PRODUCTION PLANNING \& CONTROL, 26, 13, pp1090-1109.

\begin{abstract}
:
Collaborative planning, forecasting and replenishment (CPFR) is one of the most important, but also one of the most difficult collaborative strategies in supply chain management. CPFR has been well documented in past research as providing significant benefit to those that implement it well. It has also been noted that CPFR take up has been significantly lower than initially expected. The main reason for this slow up take is the general recognition that successful implementation of CPFR is not a trivial task and the fact that it inflicts dramatic changes to the 'usual' way of doing business. Based on the premise that CPFR has significant positive potential for supply chain collaboration, the motivation of this paper is to review CPFR enablers and to develop a model which addresses the most significant ones. To complete this task a hybrid modeling approach integrating fuzzy extended analytical hierarchy process (FEAHP) and interpretive structural modeling (ISM) is proposed. The model developed is based on an identified gap by the automotive sector and embeds expert opinion, from two separate industrial groups in the automotive sector through the use of workshops. Although potential success factors for CPFR implementation can vary across somewhat between differing supply chains, the results maintain wider general applicability due to the many common issues across sectors. The paper highlights the need for decision makers to be aware of the most influential enablers prior to a CPFR implementation project and to understand the relationships between these enablers.
\end{abstract}

Keywords: CPFR implementation enablers, CPFR workshops; FEAHP, interpretive structural modelling

\section{Introduction}

Increasingly improving overall operational performance is a main objective for most supply chains. Supply chains and hence trading partners achieve this goal by delivering a product or service to the ultimate customer at minimal cost and at the required time. It has been well documented by researchers to date that effective supply chain management (SCM) requires coordination and collaboration among these various trading partners including retailers, suppliers, manufacturers, and other chain members (Liston et al. 2008). In order to achieve sustainable relationships, various industrial collaborative practices have been devised and tested. These include for example, efficient customer response (ECR), vendor managed inventory (VMI), and collaborative planning, forecasting and replenishment (CPFR). CPFR combines the intelligence of multiple trading partners in the planning and fulfilment of customer demand and is generally acknowledged as the most powerful collaboration technique. CPFR can solve the majority of the problems that are encountered in the adaptation of ECR and VMI because it requires all members of a supply chain to jointly develop demand forecasts, production and purchasing plans, and inventory replenishments (Aviv, 2002; Sari, 2008). CPFR emphasises partnership activities between all members in the supply chain in order to achieve greater shared benefits (Cassivi, 2006).

A steady stream of reports on successful industrial implementations of CPFR and experiences have been reported in the literature since its original conception as a technique (McCarthy and Golicic, 2002; Lin et al. 2004; Chung and Leung, 2005; Wang et al. 2005; Danese, 2006; Cederlund et al. 2007; Du et al. 2009; Fang and Meng, 2010; Fu et al. 2010; Jiang and Ying, 2012). Although CPFR has been shown to facilitate supply chain advances such as: enabling maximization of total network profit (Lehoux et al. 2014); improved forecasting accuracy (Småros, 2003); enhanced customer service quality (Du et al. 2009); greater product availability assurance (McCarthy and Golicic, 2002) 
and reduced replenishment frequency (Wei et al. 2010), the implementation rate from its introduction in 1998 has recently been reported as being significantly slower than expected (Småros, 2003; Büyüközkan and Vardaloğlu, 2012). Based on the well documented premise of CPFR value and the apparent contradiction in terms of limited implementations, the motivation of this paper is to identify and analyse CPFR enablers based around a supply chain sector where close collaboration is deemed essential to successful operation. For the purpose of this study the automotive supply chain has been analysed to develop a model which addresses the most significant identified enablers and rank the most dominant ones, prior to the CPFR implementation phase. The automotive supply chain is highly capitalised and technical intensive (Luh et al. 2007) and characterized by intense global competition at which collaboration between trading partners is important for this industry (Binder and Clegg 2007). Earlier research identified the importance of collaboration (Binder et al. 2008; Salzmann et al. 2009) and information exchange (Aigbedo and Tanniru, 2005; Luh et al. 2007) in automotive industry.

Following a comprehensive literature review, the significant enablers reported in previous papers have been identified. A hybrid modeling approach integrating fuzzy extended analytical hierarchy process (FEAHP) and interpretive structural modeling (ISM) is then proposed to develop the contextual relationships between the identified enablers and MICMAC (Matrice d'Impacts Croisés Multiplication Appliquée à un Classement) for enablers classification based upon the driving and dependence powers.

\section{Literature review}

As a technique, CPFR originated from the Voluntary Inter-industry Commerce Standards (VICS) in 1998 (VICS 2013). At the outset VICS described CPFR as "a collection of new business practices that leverage the Internet and EDI in order to radically reduce inventories and expenses while improving customer service". In the years following 1998, a number of authors have placed their own definitions on CPFR, but almost all can be traced back to derivations of the original. What is clear from the definitions is that CPFR is intended as a common platform, is multi party and is an attempt to coordinate for advanced performance. What is central to each of these activities is information sharing and if executed appropriately has the potential to enable significant performance benefits across the chain (Byrne and Heavey 2006; Aviv 2002, 2007; Zhu et al. 2011). In the domain of CPFR, Yuan et al (2010) demonstrated that CPFR by necessity places significant attention on the sharing of customer demand information among all trading partners, with the manufacturer coordinating activities from the production operation plans to enhance the efficiency of the supply chain. Although collaborative schemes have originated from and still tend to focus on the grocery sector (Fliedner 2003; Chen et al. 2007; Småros 2007), a wide number of other sectors have used and benefited from CPFR implementation, as examples, the automotive (Dannenberg and Kleinhans 2004; Liker and Wu 2006; Paqarizi and Hsu 2013), apparel (Ding et al. 2011), agricultural (Du et al. 2009; Fang and Meng 2010) and hospital (Lin and Ho 2014) supply chains.

It is generally recognised that successful implementation of CPFR is not a trivial task, consuming significant organisational resources, requiring mutual trust between trading partners and inflicting dramatic changes to the 'usual' way of doing business (Fliedner 2003; Sari, 2008). It has been suggested by Sari (2008) that the reported high development and operational costs in combination with greater implementation difficulties may explain why many of the CPFR programms have not moved beyond a limited number of product categories or a small set of trading partners. In addition, the lack of standard application both within and across industries causes its own difficulties (Danese 2006, 2007). In these two studies, seven cases and six different types of CPFR collaborations were identified. When analysed it was found that the choice can be explained by considering a number of 
important contingent factors, which included CPFR goals, characteristics of the products and markets in which they are sold, the supply networks physical and relational structure, and the CPFR development stage.

Although there has been a recognition of a below expectation take up of CPFR in the industrial world the literature has conversely also been devoid of material focusing on CPFR enablers and/or barriers that may address this. Most studies simply focus on an analysis of the success itself. In recent times three studies have been presented which have begun to review CPFR in slightly broader terms (Fu et al. 2010; Lin and Ho, 2014; Panahifar et al. 2014). The study of Fu et al (2010) was conducted in the retail sector using Fuzzy AHP. Their study highlighted a number of enablers for CPFR implementation, which included: cross-department communication and collaboration capability; change management; organisation innovation capability; system complexity; mutual objectives; amalgamation capability of technology and culture; top management support; trust and communication; system security and electronic data interchange. Lin and Ho (2014), using a modeling and survey method in the healthcare sector put forward a model for CPFR implementation. Their study highlighted the role of trust as a major hindrance and technology as one of the main factors in expediting effective CPFR implementation. The study also shows that upfront planning (including a pilot) is a key success factor. Panahifar et al (2014) explored the most dominant barriers to the implementation of CPFR in high-tech industries. As part of this study they presented 45 barriers which were reduced to the 13 most significant barriers and their hierarchical relationships through ISM model development. Of the barriers identified, the managerial barriers of 'lack of visible and effective leadership' was found to be the most strategic and critical barrier and which leads to other cultural and process barriers.

This paper proposes to address this identified gap by carrying out an industrial based study on CPFR enablers in the automotive sector. In particular this study will draw on supply chain expertise to develop a model which can be used to clearly identify CPFR implementation enablers thus bridging the gap between CPFR potential and CPFR enablement. The modeling approaches used embed industrial expertise into the process throughout.

\section{Modeling Approach}

Hybrid models in this domain are relatively new in the literature but have been widely used in the recent past. Of those presented in the literature to date, a sample is presented here. Huang et al (2005) proposed a hybrid approach by integrating ISM and an analytical network process (ANP) to analyse the interdependence of subsystems and feedback relationships. Noorul Haq and Kannan (2006) applied the ISM method and FAHP and proposed a model for evaluating vendor selection. In a similar but unrelated study Yang et al (2008), proposed the same hybrid methods (ISM and FAHP), also for the vender selection process. They first used triangular fuzzy numbers to express the subjective preferences of evaluators. Secondly, they utilized interpretive structural modeling (ISM) to map out the relationships among the sub criteria. Again using ISM and FAHP, Cheng et al (2007) proposed a method to evaluate worker productivity. Kannan et al (2009) developed a multi-criteria group decision making (MCGDM) model in a fuzzy environment to guide the selection process for the best third-party reverse logistics providers.

Multi criteria decision-making (MCDM) is involved with the process of ranking any kind of elements related to various field of studies specially supply chain management (Lirn et al. 2003; Bottani and Rizzi, 2005; Panahifar et al. 2013; Ghadimi and Heavey, 2014). The analytic hierarchy process (AHP) method plays a major role in MCDM methods which is based on pairwise comparisons as it was firstly developed by Saaty (1980) with the advantages of ranking both intangible and tangible elements and sub elements. On the contrary, AHP would encounter 
difficulties in addressing the problem of uncertainty in human thoughts. This issue was addressed by the development of FEAHP (Chang 1996).

[Place Figure 1 about here]

[Place Figure 2 about here]

ISM is a computer-assisted learning process that enables individuals or groups to develop a map of the complex relationships between several factors of a complex system or phenomenon (Kannan et al 2009; Govindan et al 2012). ISM aims to decompose a complicated system into several simple subsystems by using experts' opinion and knowledge in order to construct a multi-level structural model. As described by Panahifar et al (2014), ISM is an advanced planning methodology applied to identify and summarise the relationships between identified variables used to define a problem or issue. This technique is also useful where the opinions and judgements of experts and practitioners are needed to gain a consensus. To date, ISM has been widely applied to study and identify both enablers and barriers in a number of different research areas, which includes: reverse logistics barriers - Ravi and Shankar (2005); automotive barriers - Jharkharia and Shankar (2005); bio-energy barriers - McCormick and Kaberger (2007); energy saving - Wang et al (2008); IT in SMEs Thakkar et al (2008); green supply chain management - Luthra et al (2011) and Mathiyazhagan et al (2013); enablers of world-class manufacturing practices - Haleema et al (2012) and barriers in the high tech sector - Panahifar et al (2014).

The literature review has shown that only a small number of papers have made initial attempts to address the issue of identifying CSFs for CPFR implementation (Wang et al, 2005; Fu et al, 2010, Lin and Ho, 2014). This paper, addresses this gap by identifying an extended list of CPFR implementation enablers and analyzing using the hybrid model (FEAHP and ISM) developed as part of this research. A brief definition and description of each identified factor is presented in Table 1. This extended list was developed from a comprehensive literature review and the inclusion of expert opinion obtained from two groups of experts in the automotive spare parts industry who were assembled for the purpose of this study (see Figure 1 and 2 for the complete modeling approach). For the analysis, the views of the first group of experts were applied for the identification of the main enablers. Then, in the next step, the FEAHP approach was used to weight the selected elements and sub elements. The relative importance of different decision criteria involves a high degree of subjective judgement and individual preferences. The linguistic assessment of human feelings and judgements are vague and it is not reasonable to represent them in terms of precise numbers, but to position them as interval judgements. Therefore, triangular fuzzy numbers were used in this problem to decide the priority of one decision variable over another. The synthetic extent analysis method was then used to decide the final priority weights based on triangular fuzzy numbers and the FEAHP method. Finally, from this the top fifteen enablers for CPFR implementation in an automotive setting were identified.

Increasing the number of experts could result in more stability and reliability in the results of proposed method. For this reason, the ISM methodology was then applied to select the fifteen most 
important factors using the second group of experts (supply chain management and automotive manufacturing sectors). After evaluation of each set of responses, ten mutual criteria have been selected for further analysis. This analysis is based on the development of a Structural Self Interaction Matrix (SSIM) and the completion of the ISM approach with MICMAC analysis. An independent group (Expert Group 3) was finally used for the purpose of ISM model and results validation and for identifications of practical implications. This section surveys experts with extensive knowledge on CPFR implementation and with over 20 years of experience on international marketplace. Through in-depth interviews with the experts, this study obtains their perceptions on the current status, practical implications and future directions of the proposed model.

[Place Table 1 about here]

[Place Table 2 about here]

\section{Development of the hybrid solution methodology}

The methodological framework in this study is based largely on expert opinion and perception and includes three supporting techniques: Literature review, Fuzzy techniques and the ISM approach. The main steps of this hybrid method are presented in Figure 1 and Figure 2 (including the main ISM development phases). The relevant elements and sub elements have been determined based on literature studies and through consultation with the first expert group. This consultation took place where each of the potentially important elements which could affect the implementation of CPFR was discussed. This group consisted of six experts, four of whom were from industry (two supply chain directors, one production manager and one sales manager) and two active academic research experts (fully aware of the CPFR implementation process in industry). By combining the elements determined by the experts and the elements already identified in the literature, the main elements and the sub elements in this study were determined (Table 1).

Using expert opinion, two dimensions have been defined, intra-company indicators and intercompany indicators. These, two dimensions have been further classified into two sub elements (level one), namely technological and non-technological. In completing their analysis the expert group have decomposed these elements into a further 24 sub elements (level 2), which are derived from one of the level one categories. These elements and sub elements and their literature counterparts are presented in Table 2 . 
The elements and sub elements for CPFR implementation are then weighted using FEAHP. In developing these weights the six experts as a collective group were asked to make pairwise comparisons on the relative importance between each of the elements and sub elements. This comparison began with the two dimensions for CPFR implementation, then the elements with respect to the dimensions and finally the sub elements with respect to the elements. These comparisons were captured through the linguistic variables and translated to a fuzzy scale as presented in Table 3. Using the hierarchical structure developed in Table 2, and the fuzzy AHP methodology, the fuzzy evaluation matrices for each of the elements, sub elements were constructed $\left(A_{1}-\right.$ Table $4 ; A_{2}-$ Table5; $B_{1}-$ Table6; $B_{2}-$ Table7). From these and based on Chang's FEAHP steps (Chang 1996), the dimensions, elements and sub elements have been developed and the overall global weights calculated (Table 8). The ranked order for these sub elements is presented in Table 9.

In parallel to the activities of group one, the second group of experts (with 7 members) was independently tasked with identifying the most important enablers and the nature of their contextual relationships in relation to the CPFR implementation process. This group consisted of five experts from the automotive industry and two from academia. These experts each had a minimum of 10 years of experience in different sectors of the automotive industry. The industry experts included an executive manager for the sales sector, two experts from the production planning and operations departments and two experts from the cost engineering and sales departments.

[Place Table 4 about here]

[Place Table 5 about here]

[Place Table 6 about here]

[Place Table 7 about here]

[Place Table 8 about here]

[Place Table 9 about here]

[Place Table 10 about here]

In completing this task the initial stage of the ISM methodology was used. The ISM methodology emphasises the experts' views and perceptions by using different management techniques such as brain storming and the Nominal Group Technique (NGT). The NGT is a powerful learning and development tool which developed as an organisational planning tool (Tuffrey-Wijne et al. 2007). For this group (group two), an NGT session was conducted, in order to generate and select the 
enablers related to the CPFR implementation process with the aim of reaching an expert consensus position. To facilitate this process the session was opened with a trigger question 'what are the important enablers for adopting CPFR in automotive industries'? The NGT session then proceeded and included the generating of ideas individually; exchanging lists of enablers; identifying headings for categorising the enablers; and editing the ideas generated. In this session, the experts were also tasked with narrowing down their initial list to a consensus list of 15 of the most important enablers. Table 10 presents the 15 most important enablers as identified by the second group and the number of votes for each enabler. The votes were cast privately by each of the 7 individual experts in group two $\left(E_{1}, E_{2}, \ldots E_{7}\right)$ using a 1 to 5 scale with 1 representing 'Not Important' and 5 representing 'Very Important'. The 15 CPFR enablers are then ranked accordingly to the highest total votes.

Following the separate identification and ranking of 15 CPFR enablers by both expert groups the next step of the study was the consolidation of these two separate lists into a single list containing the most common mutuall factors identified. From an analysis of the mutual CPFR enablers (Table 9 and Table 10) it can be seen that there are 10 which can be identified and selected. These 10 mutual CPFR enablers are then brought forward to the next stages of the ISM methodology. A second workshop session was organised where both expert groups were brought together to study the relationship among these 10 selected enablers. In this workshop the experts were questioned about the causal relationship among each of these enablers. Specifically, they were asked does enabler $i$ significantly ameliorate enabler $j$, where $i$ and $j$ represent each of the 10 enablers respectively. In order to support this activity descriptors/definitions from the literature for each of the 10 different enablers (see Table 1) were presented to the expert participants so as to have a common understanding across the entire grouping. To analyse the enablers a contextual relationship of "ameliorate" is chosen. The following four symbols have been used to denote the direction of relationship between enablers $(i$ and $j$ ):
$\mathrm{V}$ : enabler $i$ will ameliorate enabler $j$;
A: enabler $j$ will ameliorate enabler $i$;
$\mathrm{X}$ : enabler $i$ and $j$ will ameliorate each other; and
$\mathrm{O}$ : enabler $i$ and enabler $j$ are unrelated.

The Structural Self-interaction Matrix (SSIM) and subsequent steps of the ISM were completed using the ISM software GMU (windows version). The ISM software is simple and user-friendly software with the ability to build the final reachability matrix from the SSIM matrix. The outcome from the SSIM is shown in Table 11. It can be seen for example that expert opinion was that "developing IT infrastructure" will ameliorate "information accuracy" and that "information security" and "clear communication plan" will ameliorate "high level of trust" and that "high level of trust" and "information accuracy" ameliorate each other. The conversion of the SSIM into a binary matrix, called the reachability matrix (Table 12) is completed by substituting V, A, X, O by 1 or 0.

The rules to build this table are:

If $\operatorname{SSIM}(i, j)$ is $\mathrm{V},(i, j)$ then the reachability matrix will be 1 and $(j, i)$ value will be 0 . If $\operatorname{SSIM}(i, j)$ is $A,(i, j)$ then the reachability matrix will be 0 and $(j, i)$ value will be 1 . If $\operatorname{SSIM}(i, j)$ is $X,(i, j)$ then the reachability matrix will be 1 and $(j, i)$ value will be 1 . If $\operatorname{SSIM}(i, j)$ is $O,(i, j)$ then the reachability matrix will be 0 and $(j, i)$ value will be 0 . 
This is followed by a transitivity check. If enabler $(x)$ leads to enabler $(y)$ and enabler $(y)$ leads to enable $(z)$, then enabler $(x)$ should lead to enabler $(z)$. The ISM software GMU (Broome 1999), generates this final reachability matrix from the initial SSIM matrix.

The reachability set, antecedent set and intersections are found to determine the level of each enabler from the final reachability matrix. The reachability set consists of the element itself and other elements to which it may reach (looking across the rows), whereas the antecedent set consists of the element itself and the other elements which may reach to it (looking down the columns), (Mandal and Deshmukh, 1994). For example in Iteration 1 (Table 13), the reachability set for 'enabler 1' is 1,7 (from row 1 in Table 12), and the antecedent set is 1,2,3,4,5,6,7,9,10 (from column 1 in Table 12). The intersection is the common set of barriers in both the reachability and antecedent sets. When a reachability set is repeated in the intersection set, this barrier will be selected as the current top position in the ISM hierarchy model. (e.g. at the start-level 1). These are then removed from the reachability and antecedent set of the remaining enablers. From Table 13, it is seen that three enablers were found to be at level I. In a continuation of this activity to its conclusion five levels were identified and are presented in Tables $13-17$.

[Place Table 11 about here]

[Place Table 12 about here]

[Place Table 13 about here]

[Place Table 14 about here]

[Place Table 15 about here]

[Place Table 16 about here]

[Place Table 17 about here]

\subsection{MICMAC analysis}

MICMAC classment (cross-impact matrix multiplication applied to classification) is a technique developed to measure the importance of variables by analyzing the driving and the dependence power of the variable (Mandal and Deshmukh, 1994). In this study, this has been completed to 
identify the key enablers that drive CPFR implementation. Different variables are classified into four clusters consisting of "autonomous enablers", "dependent enables", "linkage enablers" and "driver enablers" based on their driver power and dependence. As Figure 3 shows, the first cluster consists of the autonomous enablers (bottom left quadrant) that have weak driver power and weak dependence. Autonomous enablers are relatively disconnected from the system, where they have only a few links, some of which may be strong. In this study, there are no autonomous enablers in the first cluster. The second quadrant is termed dependent variables (bottom right quadrant) and consists of variables which have weak driver power but strong dependence. The third cluster (top right quadrant) has the linkage criteria as they have a strong driving power and also a strong dependence. These criteria are regarded as unstable as any action that has an effect on these criteria will also have an effect on other criteria and also a feedback effect on themselves. The fourth cluster (top left quadrant) has strong driving power and weak dependence power and is the independent variables. It is observed that a variable with a very strong driving power called the key variables, falls into the category of independent or linkage criteria. The driver power-dependence diagram for this study is constructed using the information presented in Table 12.

[Place Figure 3 about here]

\subsection{ISM final model formulation}

The level of each enabler has been determined through the ISM process as depicted in Tables 13 17. From the final reachability matrix (Table 12), the structural model is generated to provide a better understanding of the inter-relationships among the enablers. If there is a relationship between the enablers $j$, and $i$ this is shown by an arrow which points from $i$ to $j$. This graph is called a graph or digraph. In this step, the transitivity will be removed as described in the ISM methodology. The digraph is finally converted into ISM model as shown in Figure 4. It is observed from this digraph that "competition pressure" is a very significant enabler for CPFR implementation in automotive industries as it is at the root of the ISM hierarchy.

[Place Figure 4 about here]

\section{Industrial validation and implications for practice}

In order to ensure model integrity a third expert group was engaged in model validation. The membership of this expert grouping was independent of both expert groups one and two so as to prevent individual bias (as a result of model development activities). In order to examine the 
effectiveness of the proposed CPFR implementation in-depth interviews were conducted with this third expert group. The main purpose of the in-depth interviews was to: 1) validate the general conceptual model and findings from the model development; 2) obtain experts' perceptions on the practical implications for industry and 3) identify and improvements that could be made to the model. The third expert group consists of highly skilled practitioners, each with over 20 years of experience working in an international marketplace. The interviews were conducted through the use of an initial questionnaire, followed by face-to-face interviews. Topics that were discussed included the importance of identified enablers in reality and the possible significant interrelationships between identified enablers. To gain insights into the practical and managerial implications of the model, interviewees were asked whether in their opinion the proposed model is indicative of actual CPFR enablers during its implementation process. In general, the expert group validated the findings as an appropriate representation of standard industry practice, with all three interviewees considering the CPFR implementation enablers model to be a pragmatic solution for exploring the sophisticated interactions between identified enablers. From this the general conceptual model was validated and expert viewpoints recorded. The findings from these interviews are summarized in the following paragraphs.

The model validation group suggested that using this proposed model, companies will be better able to understand the factors that affect CPFR implementation and hence prioritise management attention to the most significant factors prior to CPFR adoption. The results also highlight areas that companies can focus on in order to improve collaboration performance and results by reinforcing dominant enablers. For example, managers should make special efforts and dedicate extra resources at the outset for the purpose of enhancing information sharing security with their partners, because a secured information sharing system plays a significant enabling role in successful CPFR implementation. Effective use of the proposed model should inform breakthrough strategies for CPFR implementation. The results from this study have also shown that having a high level of trust at the early stage of CPFR adoption is not always possible. Consequently, managers should focus significant efforts on enhancing communication and trust with trading partners, particularly in pre and shortly after initial CPFR engagement.

The interviewees confirmed that from a practical perspective, the proposed model will enhance a firms' ability to implement CPFR strategies successfully. It was also noted that significant resources are required and must be targeted at the most important issues. In many instances firms who wish to implement CPFR will suffer from limited resources. In those instances the model presented in this paper is crucial in assisting in optimally assigning those scarce resources. The findings also suggest that senior management need to recognise that the CPFR implementation process is enhanced by integrating various internal and external capabilities and resources. The proposed model in this paper will assist companies in setting up an appropriate time framework to implement CPFR based on identified organisational capabilities.

\section{Findings and Discussion}

The literature clearly highlights the significant added value that a supply chain can achieve from correct implementation of CPFR, but also conversely opines that it appears to not have been taken up as much as originally anticipated. CPFR by its nature is a large resource consuming process and one that needs careful fore planning to facilitate success. Based on this premise, this paper has reviewed and analysed CPFR key enablers, which organisations must consider and plan for. For CPFR to be more successfully implemented there is a need for practitioners to better understand these factors and their relevant interactions prior to CPFR engagement. In order to design a more effective decisionmaking process, this study applied a hybrid approach to the study of CPFR implementation enablers. 
In this paper, 24 distinct enablers have been identified, which have been reduced to 10 through the use of Fuzzy AHP and ISM modelling, including expert opinion. To complete this task, this paper has engaged three separate groups of CPFR experts and utilized a hybrid modeling approach to identify and analyse the most significant CPFR implementation enablers and their interactions. The driving power and dependence diagram (Figure 3) presents valuable insights into the importance and the interdependencies among these enablers. In a situation of limited resources, executives have to take into account optimal resource allocation due to the large number of enablers prior to CPFR implementation. This framework assists significantly in this task.

In this study, competition pressure was found to be the most significant implementation enabler. Ironically this is one of the factors that an organisation can have little individual effect on. From further analysis of this phenomenon it is observed that in a strong competitive environment, it appears easier to move to the next most significant enabler "senior management support and commitment". This in turn drives the willingness to collaborate and a need to have a clear communication plan among partners, and which also contributes towards willingness towards CPFR investment. This would suggest that the ideal scenario for CPFR engagement would be highly competitive environments in the first instance. Senior management support and commitment is one of the most dominant enablers which lead to almost all other enablers resulting in competitive advantage. It has a high driving power and an intensified relationship with nine other enablers (See Table 12 row 9). From these findings it can be contended that "leadership" plays a critical role in successfully managing teams to promote individuals in their CPFR implementation roles and to support and encourage an internally and externally collaborative atmosphere. This finding is in line with Europe ERC (2001) which argued with respect to CPFR that "senior management support is vital to secure the necessary involvement and commitment of key resources as well as eliminate any existing organisational barriers".

It can be observed from this study that of the ten most significant enablers identified, seven of these are attributable to the non-technological dimension of CPFR implementation. This indicates that although technology is important for success, it is likely to be the non-technological dimensions which if not managed correctly can lead to ultimate failure. This aligns with the findings of Frankel et al (2002), Attaran (2012) and Panahifar et al (2014). This is an important factor that is often over looked by senior management. In summary, technology should be regarded as only a singular segment of the CPFR implementation process which plays an important role as facilitator, but technology alone is not CPFR. As an example it can be seen that "developing an IT infrastructure" is in itself a technological feat, however it can also lead to enhanced trust and facilitate information readiness by trading partners, which fall into the non- technological domains. In other words, there is little benefit from collaboration only by relying on developed technologies unless people and process change is enacted.

The model also helps to highlight the differences between what experts perceive as being 'important' and what can be categorized as 'dominant' following hybrid model development. This is an important distinction as it facilitates the more appropriate assignment of scarce resources to relevant enablers. In the absence of this model all enablers can be considered important with no available guidance on prioritization. As an example to this, the enabler 'high level of trust' was ranked as an important factor by the first two expert groups in the earlier parts of the study, however as it was not considered to be a driver of other factors, it has been located near the summit of the hierarchical model. From a practical perspective this indicates that building up trust between partners is dependent on and is reinforced through many other factors and is not improved in isolation. Although companies need to have a degree of trust to begin a CPFR implementation process, trust 
improves and evolves as partners move through the process successfully. In addition, CPFR requires a secure IT infrastructure for information sharing. This enables companies to circulate accurate and timely information. The ISM-based model presented suggests that organisations have to increase information security if they expect both more accurate information and a high level of trust from their trading partners. From a practical perspective, trading partners will be more reluctant to share their critical information in an insecure environment. Thus, the more secure the information sharing system the more accurate information is likely to be.

The ISM model also presents a number of enablers that significantly help to ameliorate each other. For instance a, 'high level of trust' and 'information accuracy' helps to improve each other. In other words, the higher the level of trust, the more accurate information is likely to be and vice versa. In these instances such enablers have mutual beneficial connectors where a positive movement in one will lead to a positive movement in the other. However, from a practical perspective this can also occur in the negative. For example a negative experience in one can have a similarly negative consequence on the other. This again is one of the suggested reasons for many CPFR failures. Almost like a house of cards a deficit in one area can quickly lead to deficits throughout the model and ultimately an unsuccessful CPFR implementation. For this reason it is imperative that senior management is aware of these connectors and account for them in the project management phase of any CPFR implementations.

It should also be noted that the MICMAC analyse (Figure 3) has identified no autonomous enablers. The absence of autonomous enablers highlights the fact that all identified enablers do in fact significantly influence the CPFR implementation process in the automotive spare parts supply chain. For successful CPFR implementation each of these enablers should be individually reviewed with plans of action drawn up for each taking into consideration their individual importance in the presented hierarchy. Too often CPFR implementation initiatives have failed to progress due to an over focus on the technological challenges, at the expense of the non-technological. This paper clearly discusses the implications of this strategy and highlights to practitioners the need for a more balanced approach with a particular need to focus more attention on the non-technological dimensions.

As with all studies there exist some limitations. In the case of this paper the current study focused its attentions on the automotive sector. Although it is posited that the findings are likely to have wider general applicability due to the nature of the modelling process and the expert groups used, this is an assertion which needs to be validated by replicating this study in other industries. Although the models presented have been validated by a third expert group, a separate case study should be completed to fully test these models tools in a real world implementation process. This in itself is well outside the scope of this paper and could lead to a number of separate studies and papers in its own right. In addition the current model identifies a hierarchical framework for enabler prioritisation. This has been currently developed in a static fashion with each of the enablers linked throughout the framework. More research is needed to study the dynamic interactions between identified enablers and the movement of status of position at varying stages of CPFR engagement - e.g. planning, implementation, execution and also given varied success across each of the individual factors.

Acknowledgement: For this research, Prof. Cathal Heavey has been co-financed by the European Union (European Social Fund - ESF) and Greek national funds through the Operational Program "Education and Lifelong Learning" of the National Strategic Reference Framework (NSRF) - Research Funding Program: Thales: ASPASIA project. Investing in knowledge society through the European Social Fund. 


\section{References}

Aigbedo, H., and Tanniru, M. 2004. "Electronic markets in support of procurement processes along the automotive supply chain." Production Planning \& Control 15(7): 688-695.

Attaran, M. 2004. "Nurturing the supply chain." Industrial Management 46: 16-20.

Attaran, M. 2012. "Critical success factors and challenges of implementing RFID in supply chain management." Journal of Supply Chain and Operations Management 10(1): 144-169.

Attaran, M., and Attaran, S. 2007. "Collaborative supply chain management: the most promising practice for building efficient and sustainable supply chains.” Business Process Management Journal 13(3): 390-404.

Aviv, Y. 2002. "Gaining benefits from joint forecasting and replenishment processes: The case of auto-correlated demand." Manufacturing and Service Operations Management 4(1): 55-74.

Aviv, Y. 2007. "On the benefits of collaborative forecasting partnerships between retailers and manufacturers." Management Science 53(5): 777-794.

Barratt, M. 2004. "Unveiling enablers and inhibitors of collaborative planning." International Journal of Logistics Management 15(1): 73-90.

Binder, M., and Clegg, B. 2007. "Designing and managing collaborative enterprises in the automotive industry." International Journal of Logistics 10(2): 135-152.

Binder, M., Gust, P., and Clegg, B. 2008. "The importance of collaborative frontloading in automotive supply networks." Journal of Manufacturing Technology Management 19(3): 315-331.

Bottani, E., and Rizzi, A. 2005. "A fuzzy multi-attribute framework for supplier selection in an e-procurement environment." International Journal of Logistics: Research and Applications 8(3): 249-266.

Broome, Benjamin J. 1999. User's Guide to the "GMU Version" of Interpretive Structural Modeling (ISM) Software. Fairfax, VA: George Mason University.

Büyüközkan, G., and Vardaloğlu, Z. 2012. "Analyzing of CPFR success factors using fuzzy cognitive maps in retail industry." Expert Systems with Applications 39(12): 10438-10455.

Byrne, P.J., Heavey, C. 2006. "The impact of information sharing and forecasting in capacitated industrial supply chains: a case study." International Journal of Production Economics 103 (1): 420-437

Cassivi, L. 2006. "Collaboration planning in a supply chain." Supply Chain Management: An International Journal 11(3): 249-258.

Cederlund, J. P., Kohli, R., Sherer, S. A., and Yao, Y. 2007. "How Motorola put CPFR into action." Supply chain management review 11(7): 28-35.

Chang, D. Y. 1996. "Applications of the extent analysis method on fuzzy AHP." European journal of operational research 95(3): 649- 655.

Chen, M. C., Yang, T., and Li, H. C. 2007. "Evaluating the supply chain performance of IT-based inter-enterprise collaboration." Information \& Management 44(6): 524-534.

Cheng, Y. L., A. S. F. Chiu, M. L. Tseng, and Y. H. Lin., 2007. "Evaluation of worker productivity improvement using ISM and FAHP." In Industrial Engineering and Engineering Management, IEEE International Conference on, pp. 109-113. IEEE,

Chung, W. W. C., and Leung, S. W. F. 2005. "Collaborative planning, forecasting and replenishment: a case study in copper clad laminate industry." Production planning \& control 16(6): 563-574.

Danese, P. 2006. "Collaboration forms, information and communication technologies, and coordination mechanisms in CPFR." International Journal of Production Research 44(16): 3207-3226.

Danese, P. 2007. "Designing CPFR collaborations: insights from seven case studies." International Journal of Operations \& Production Management 27(2): 181-204.

Dannenberg, J., Kleinhans, C. 2004. "The coming age of collaboration in the automotive industry." Mercer Management Journal 17: 88-94.

Daugherty, P. J., Richey, R. G., Roath, A. S., Min, S., Chen, H., Arndt, A. D., and Genchev, S. E. 2006. "Is collaboration paying off for firms?" Business Horizons 49(1): 61-70.

Ding, J. H., Chen, P. S., \& Lyu, J., 2011. "Evolutionary strategy to apply information and communication technology: a case study in the apparel industry." Production Planning \& Control 22(3): 282-297.

Du, X. F., Leung, S. C., Zhang, J. L., and Lai, K. K. 2009. "Procurement of agricultural products using the CPFR approach.” Supply Chain Management: An International Journal 14(4): 253-258.

Ellinger, A. E., Daugherty, P. J., and Keller, S. B. 2000. "The relationship between marketing/logistics interdepartmental integration and performance in U. S. manufacturing firms: An empirical study." Journal of Business Logistics 21(1): $1-22$.

Europe, E. C. R., and Kronberg Accenture GmbH. 2001. “A Guide to CPFR implementation.” ECR Europe. 
Evrard-Samuel, K. 2008. "Sharing Demand Signals: A New Challenge to Improve Collaboration within Supply Chains." Supply Chain Forum: An International Journal 9(2): 16-27.

Fang, L., and Meng, X. 2010. "Research on Information Collaboration of Agricultural Supply Chains Based on CPFR." In Education Technology and Computer Science (ETCS), Second International Workshop on (3: 794-797). IEEE.

Figueiredo, P. N. (2002, May). Technological capability-accumulation and the underlying learning processes: Analytical frameworks and differences between latecomer steel firms. In Copenhagen/Elsinore: Paper presented at the DRUID Summer Conference on" Industrial Dynamics of the New and Old Economy-who is embracing whom.

Fliedner, G. 2003. "CPFR: an emerging supply chain tool.” Industrial Management \& Data Systems 103(1): 14-21.

Frankel, R., Goldsby, T. J., and Whipple, J. M. 2002. "Grocery industry collaboration in the wake of ECR." International Journal of Logistics Management 13(1): 57-72.

Fu, H. P., Chu, K. K., Lin, S. W., and Chen, C. R. 2010. "A study on factors for retailers implementing CPFR-A fuzzy AHP analysis.” Journal of Systems Science and Systems Engineering 19(2): 192-209.

Gattorna, J. (Ed.) 1998. "Strategic Supply Chain Alignment: Best Practices in Supply Chain Management." Gower, Aldershot.

Ghadimi, P., \& Heavey, C. 2014. "Sustainable Supplier Selection in Medical Device Industry: Toward Sustainable Manufacturing." Procedia CIRP, 15, 165-170.

Govindan, K., Palaniappan, M., Zhu, Q., and Kannan, D. 2012. "Analysis of third party reverse logistics provider using interpretive structural modeling." International Journal of Production Economics 140(1): 204-211.

Ha, B. C., Park, Y. K., \& Cho, S. 2011. "Suppliers' affective trust and trust in competency in buyers: its effect on collaboration and logistics efficiency." International Journal of Operations \& Production Management 31(1): 56-77.

Haleema, A., Mohammad, S., Qadric, A. and Kumarc, S. 2012. "Analysis of critical success factors of world-class manufacturing practices: an application of interpretative structural modelling and interpretative ranking process", Production Planning \& Control 23(10-11): 722-734.

Hill, C. A., \& Scudder, G. D. 2002. "The use of electronic data interchange for supply chain coordination in the food industry." Journal of Operations Management 20(4): 375-387.

Huang, J. J., Tzeng, G. H., and Ong, C. S. 2005. "Multidimensional data in multidimensional scaling using the analytic network process." Pattern Recognition Letters 26(6): 755-767.

Ireland, R., \& Bruce, R. 2000. "CPFR: only the beginning of collaboration." Supply Chain Management Review 4(4): 8088.

Jain, V., Wadhwa, S., and Deshmukh, S. G. 2009. "Revisiting information systems to support a dynamic supply chain: issues and perspectives." Production Planning and Control 20(1): 17-29.

Jharkharia, S., and Shankar, R., 2005. "IT-enablement of supply chains: understanding the barriers." Journal of Enterprise Information Management 18(1): 11-27.

Jiang, G., and Liu, Y. 2012. "Research on Collaborative Forecasting Model Based on CPFR." In Software Engineering and Knowledge Engineering: Theory and Practice 523-529. Springer Berlin Heidelberg.

Joshi, Y. V. 2000. Information visibility and its effect on supply chain dynamics (Doctoral dissertation, Massachusetts Institute of Technology).

Kannan, G., Pokharel, S., and Sasi Kumar, P. 2009. "A hybrid approach using ISM and fuzzy TOPSIS for the selection of reverse logistics provider." Resources, conservation and recycling 54(1): 28-36.

Kwon, I. W. G., and Suh, T. 2004. "Factors affecting the level of trust and commitment in supply chain relationships." Journal of Supply Chain Management 40(1): 4-14.

Kyu Kim, K., Yul Ryoo, S., and Dug Jung, M. 2011. "Inter-organisational information systems visibility in buyersupplier relationships: the case of telecommunication equipment component manufacturing industry." Omega, 39(6): 667-676.

Lehoux, N., D'Amours, S., and Langevin, A. 2014. "Inter-firm collaborations and supply chain coordination: review of key elements and case study." Production Planning \& Control 25(10): 858-872

Liker, J., and Wu, Y. C., 2006. "Japanese automakers, US suppliers and supply chain superiority." Supply chains and total product systems: a reader 177-96.

Lin, J. T., Yang, C. H., and Lin, T. M. 2004. "A CPFR implementation methodology study-a Carpenter mechanical industry case study." International Journal of Electronic Business Management 2(3/4): 172-178.

Lin, R. H., and Ho, P. Y. 2014. "The study of CPFR implementation model in medical SCM of Taiwan." Production Planning \& Control 25(3): 260-271.

Lin, R. J., Chen, R. H., and Chiu, K. K. S. 2010. "Customer relationship management and innovation capability: an empirical study." Industrial Management \& Data Systems 110(1): 111-133. 
Lirn, T. C., Thanopoulou, H. A., and Beresford, A. K. 2003. "Transhipment port selection and decision-making behaviour: analysing the Taiwanese case." International Journal of Logistics: Research and Applications 6(4): 229244.

Liston, P., Byrne, J., Heavey, C. \& Byrne, P.J. 2008. Discrete-event simulation for evaluating virtual organisations,. International Journal Of Production Research, 46, 5, pp1335-1356.

Luh, Y. P., Wang, J. B., and Chen, J. J. 2007. "The Research on Electronically Collaborative Model in Automotive Industry Supply Chain." Mechatronics and Automation 3919-3924. IEEE.

Luthra, S., Kumar, V., Kumar, S., and Haleem, A. 2011. "Barriers to implement green supply chain management in automobile industry using interpretive structural modeling technique: An Indian perspective." Journal of Industrial Engineering and Management, 4 (2): 231-257.

Mandal, A., \& Deshmukh, S. G., 1994. "Vendor selection using interpretive structural modelling (ISM)." International Journal of Operations \& Production Management 14(6): 52-59.

Mathiyazhagan, K., Govindan, K., NoorulHaq, A., and Geng, Y. 2013. "An ISM approach for the barrier analysis in implementing green supply chain management." Journal of Cleaner Production 47: 283-297.

McCarthy, T. M., and Golicic, S. L. 2002. "Implementing collaborative forecasting to improve supply chain performance." International Journal of Physical Distribution \& Logistics Management 32(6): 431-454.

McCormick, K., and Kåberger, T., 2007. "Key barriers for bioenergy in Europe: Economic conditions, know-how and institutional capacity, and supply chain co-ordination." Biomass and Bioenergy 31(7): 443-452.

Noorul Haq, A., \& Kannan, G., 2006. "An integrated approach for selecting a vendor using grey relational analysis." International Journal of Information Technology \& Decision Making 5(2): 277-295.

Palanisamy, R., and Sushil, J. L. 2003. "Measurement and enablement of information systems for organisational flexibility: an empirical study." Journal of Services Research 3(2): 82-103.

Panahifar, F., Byrne, P. J., and Heavey, C. 2014. "ISM analysis of CPFR implementation barriers". International Journal of Production Research 52(18): 5255-5272

Panahifar, F., Ghadimi, P., Azadnia, A. H., Heavey, C., \& Byrne, P. J. (2013, September). A study on CPFR implementation critical factors for the automotive spare part industry. In Modelling and Simulation (EUROSIM), 2013 8th EUROSIM Congress on (pp. 1-6). IEEE.

Panayides, P. M., and Venus Lun, Y. H. (2009). "The impact of trust on innovativeness and supply chain performance." International Journal of Production Economics 122(1): 35-46.

Paqarizi, D., and Hsu, Y. H. 2013. "Conflicting Goal and its Impact on the Level of Supply Chain Integration between Supply Chain Partners in the Automotive Industry - From Manufacturing SME's Perspective.” (Doctoral dissertation, LNU).

Petersen, K. J., Ragatz, G. L., and Monczka, R. M. 2005. "An examination of collaborative planning effectiveness and supply chain performance." Journal of Supply Chain Management 41(2): 14-25.

Ravi, V., and Shankar, R. 2005. "Analysis of interactions among the barriers of reverse logistics." Technological Forecasting and Social Change 72(8): 1011-1029.

Saaty, T. L., 1988. “What is the analytic hierarchy process?” Springer Berlin Heidelberg. (pp. 109-121)

Salzmann, H., Jacobs, J., and Froehlich, B. 2009. "Collaborative interaction in co-located two-user scenarios." In Proceedings of the 15th Joint virtual reality Eurographics conference on Virtual Environments (pp. 85-92).

Sari, K. 2008. "On the benefits of CPFR and VMI: A comparative simulation study." International Journal of Production Economics 113(2): 575-586.

Seifert, D. 2003. "Collaborative Planning, Forecasting, and Replenishment: How to Create a Supply Chain Advantage." (AMACOM Div American Mgmt Assn, Hamburg.

Småros, J. 2007. "Forecasting collaboration in the European grocery sector: Observations from a case study." Journal of Operations Management 25(3): 702-716.

Småros, J., 2003. "Collaborative forecasting: a selection of practical approaches." International Journal of Logistics: Research and Applications 6(4): 245-258.

Stank, T. P., Keller, S. B., and Daugherty, P. J. 2001. "Supply chain collaboration and logistical service performance." Journal of Business logistics 22(1): 29-48.

Stank, T.P., Daugherty, P.J and Autry, C.W. 1999. "Collaborative planning: supporting automatic replenishment programs." Supply Chain Management: An International Journal 4(2): 75-85.

Thakkar, J., Kanda, A., Deshmukh, S. G. 2008. "Interpretive structural modeling (ISM) of IT-enablers for Indian manufacturing SMEs." Information Management \& Computer Security 16(2): 113-136.

Tuffrey-Wijne, I., Bernal, J., Butler, G., Hollins, S., and Curfs, L. 2007. "Using Nominal Group Technique to investigate the views of people with intellectual disabilities on end of life care provision." Journal of advanced nursing 58(1): 80-89. 
VICS. 2013. CPFR voluntary guidelines. Voluntary Interindustry Commerce Standards (VICS) Association, Available from: http://www.vics.org/committees/cpfr/ [Accessed July 2013].

Walton, S. V., and Marucheck, A. S. 1997. "The relationship between EDI and supplier reliability." Journal of Supply Chain Management 33(3): 30-35.

Wang, G., Wang, Y., and Zhao, T. 2008. "Analysis of interactions among the barriers to energy saving in China." Energy Policy 36(6): 1879-1889.

Wang, S., and Archer, N. 2004. "Supporting collaboration in business-to-business electronic marketplaces." Information Systems and e-Business Management 2(2-3): 269-286.

Wang, W., Yuan, Y., Archer, N., and Guan, J. 2005. "Critical factors for CPFR success in the Chinese retail industry." Journal of Internet commerce 4(3): 23-39.

Wangwe, S., and es Salaam, D. 2007. "A review of methodology for assessing ICT impact on development and economic transformation." Contribution to the AERC Project on the Impact of ICTs on Economic Development and Transformation, available at: www. aercafrica. org/ documents/ ICT_project_working_papers/ Wangwe SAReview of Methodology on ICT. pdf (accessed 8 March 2012).

Wei, C. C., Sheen, G. J., Tai, C. T., and Lee, K. L. 2010. "Using Six Sigma to improve replenishment process in a direct selling company." Supply Chain Management: An International Journal 15(1): 3-9.

Whipple, J. M., and Russell, D. 2007. "Building supply chain collaboration: a typology of collaborative approaches." International Journal of Logistics Management 18(2): 174-196.

Whipple, J. M., Frankel, R., and Daugherty, P. J. 2002. "Information support for alliances: performance implications." Journal of Business Logistics 23(2): 67-82.

Wu, W. Y., Shih, H. A., and Chan, H. C. 2009. "The analytic network process for partner selection criteria in strategic alliances." Expert Systems with Applications 36(3): 4646-4653.

Yang, J. L., Chiu, H. N., Tzeng, G. H., and Yeh, R. H. 2008. "Vendor selection by integrated fuzzy MCDM techniques with independent and interdependent relationships." Information Sciences 178(21): 4166-4183.

Yuan, X., Shen, L., and Ashayeri, J. 2010. "Dynamic simulation assessment of collaboration strategies to manage demand gap in high-tech product diffusion." Robotics and Computer-Integrated Manufacturing 26(6): 647-657.

Zhu, K., Kraemer, K., and Xu, S. 2003. "Electronic business adoption by European firms: a cross-country assessment of the facilitators and inhibitors." European Journal of Information Systems 12(4): 251-268.

Zhu, X, Mukhopadhyay, S.K., Yue, X. 2011. "Role of forecast effort on supply chain profitability under various information sharing scenarios." International Journal of Production Economics 129(1): 284-291

[Place Appendix about here] 


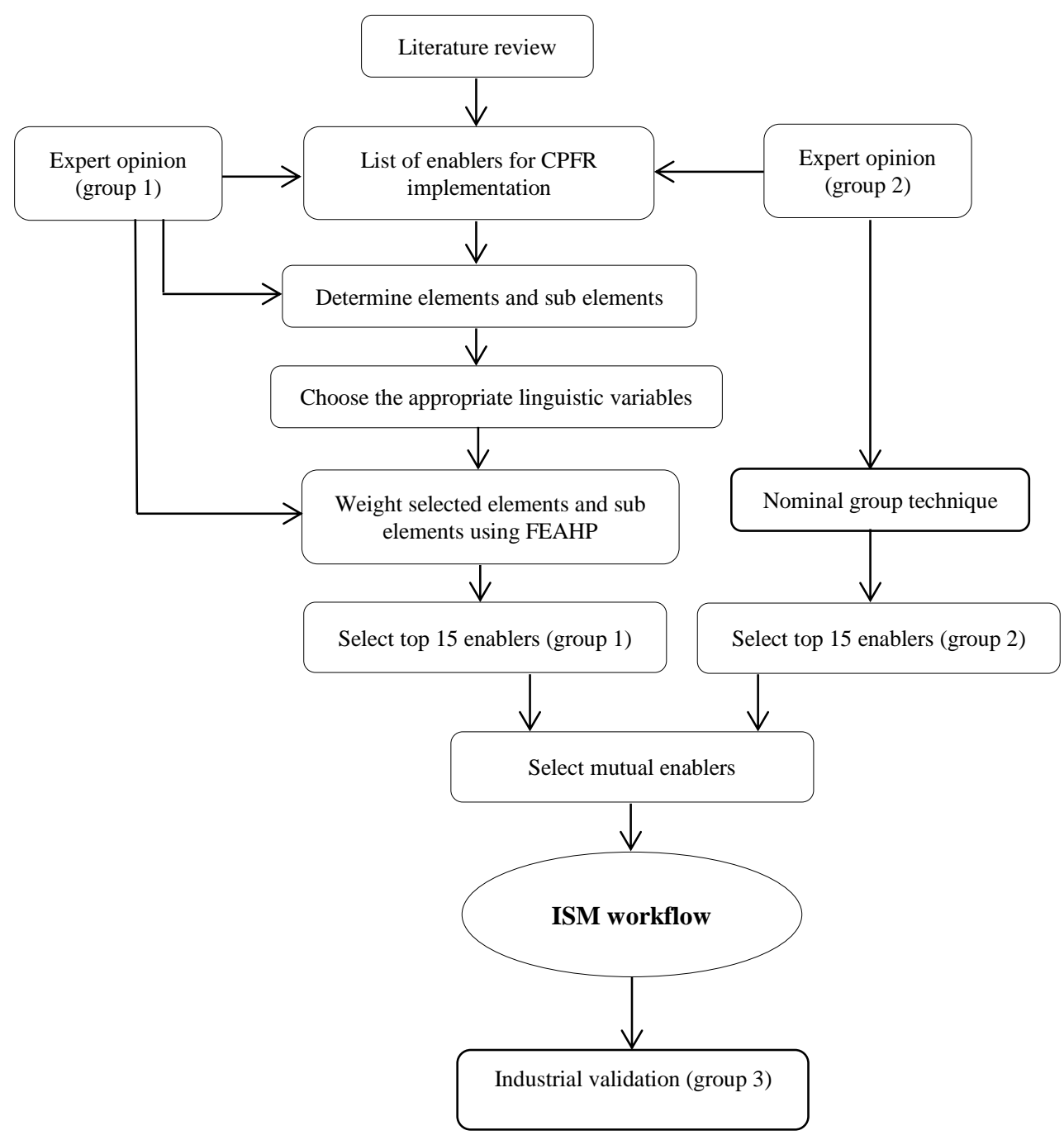

Figure 1. Research Methodology 


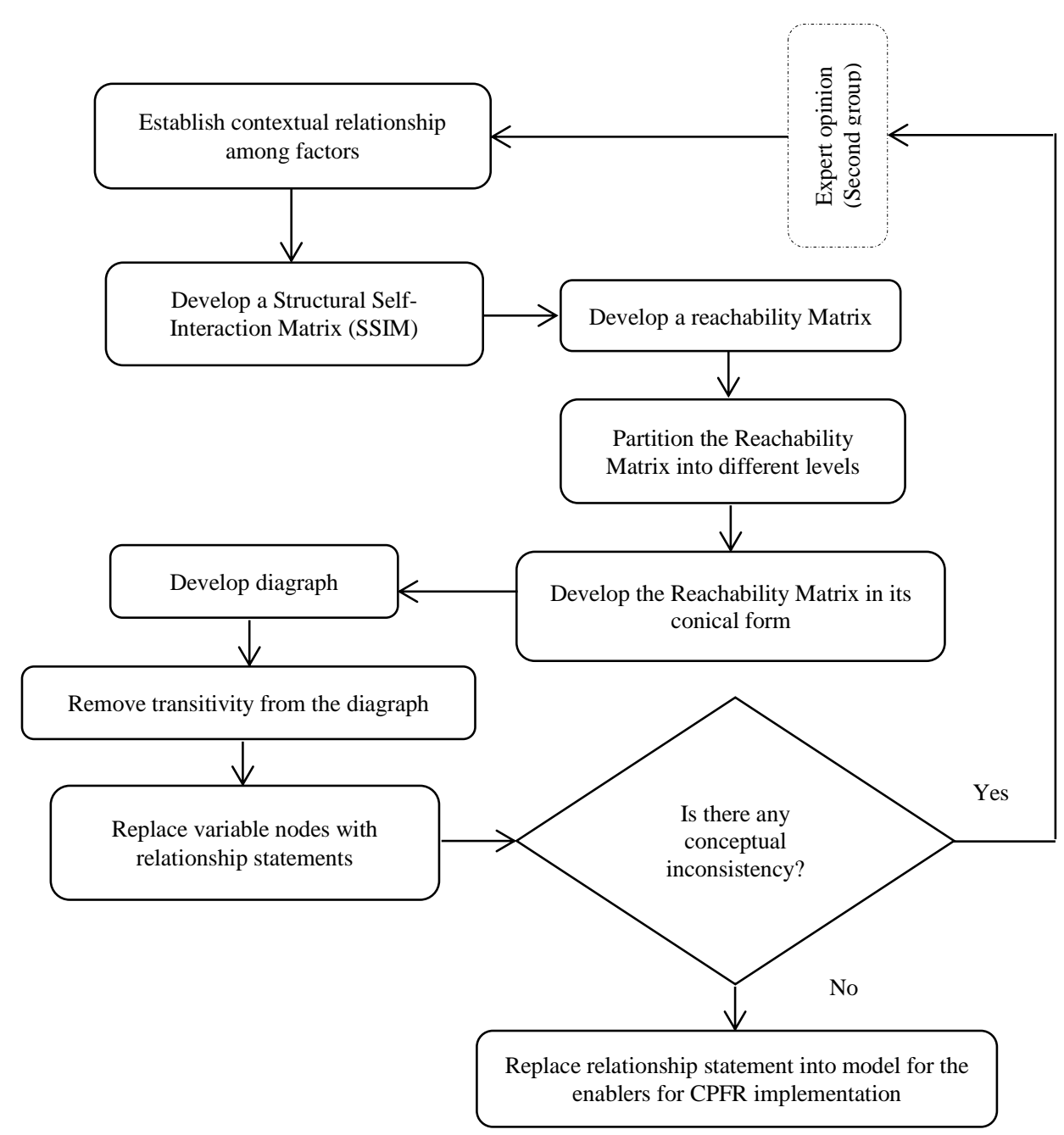

Figure 2. ISM workflow 


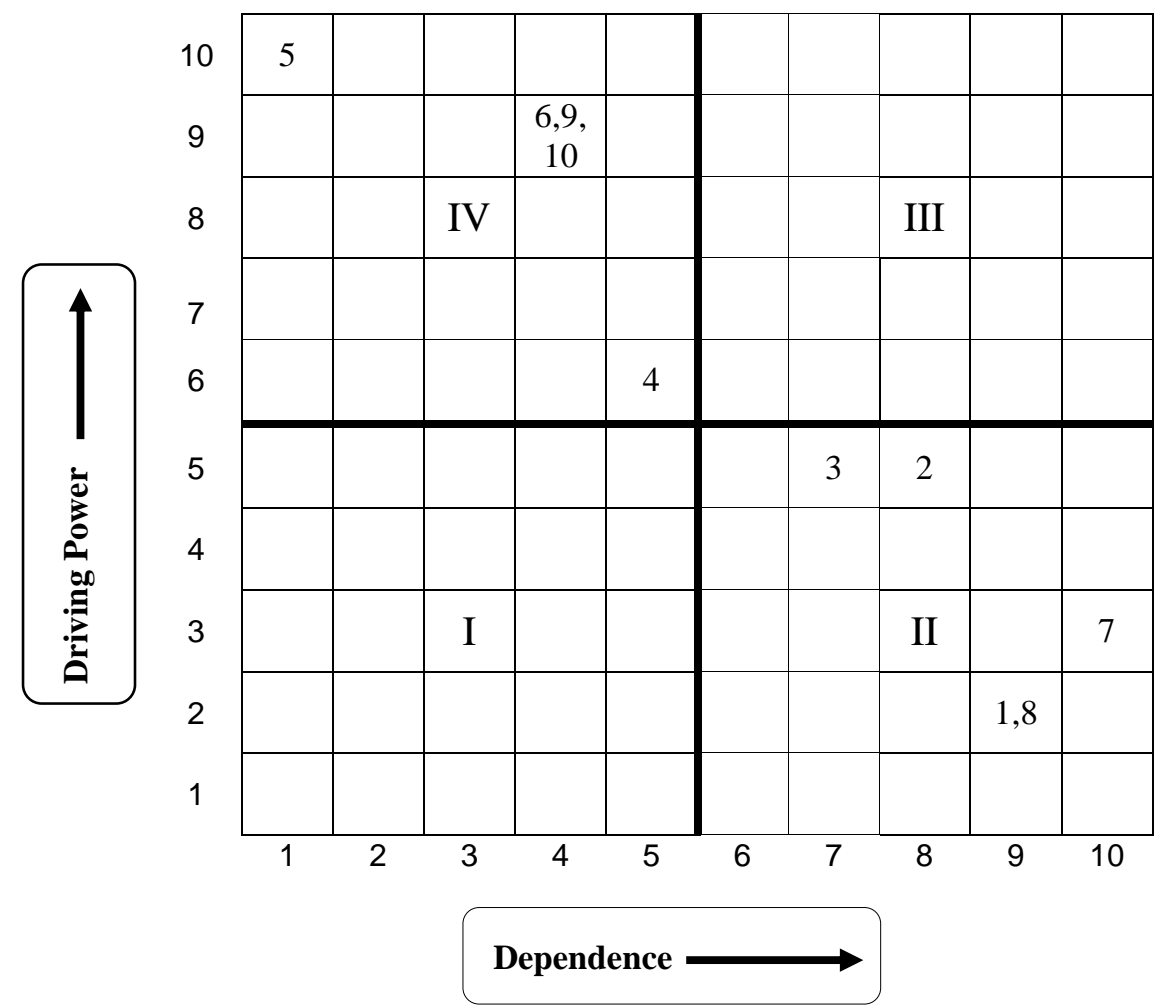

Figure 3. Driving power and dependence diagram 


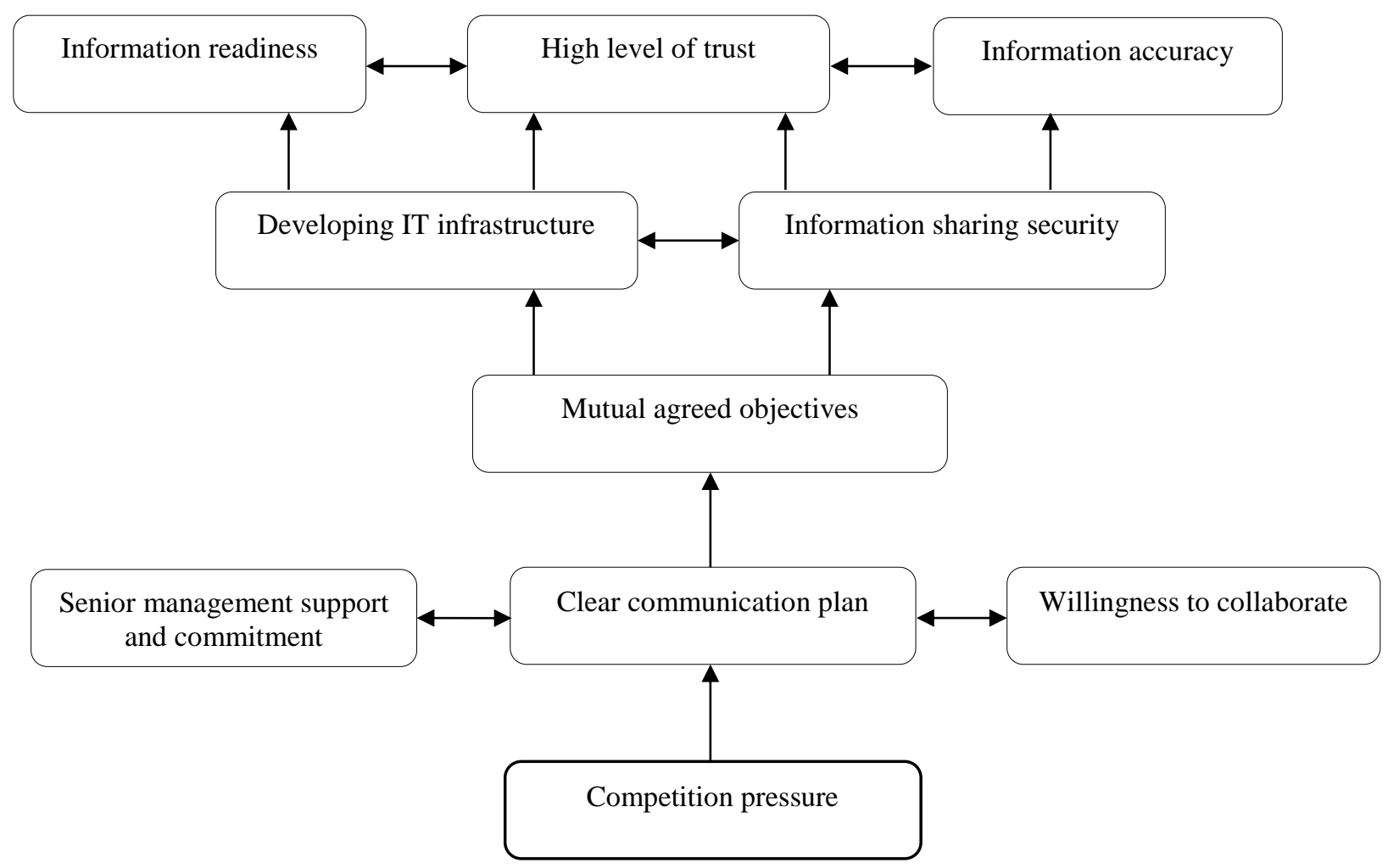

Figure 4. ISM-based model for CPFR implementation enablers 
Table 1. CPFR Enablers (Literature Review and Expert Group One).

Enabler Definition/Description

Technological capability

Information visibility

System compatibility

Amalgamation capability of technology and culture

High internal service rate Information system management

Internal alignment

Information accuracy

Willingness to collaborate

Information readiness
Technological capability is defined as embodying the resources needed to generate and manage technological change and also as an important enabler to help successfully implement collaborative practices such as CPFR (Figueiredo, 2002). This factor is also introduced by Whipple and Russell (2007) as an internal factor which may significantly affect the level of collaboration with partner election. Technological capability has been described by Wangwe et al (2007) as including: human resources capability, encompassing the ability of humans to understand technical processes, acquire the knowledge about them, interpret and adapt it to suit the local conditions and apply it creatively to the solution of practical problems.

Information visibility is defined as the degree to which the supply chain partners have on-hand information related to demand and supply for planning and control management (Kim et al. 2011). Information visibility in a supply chain aims to have the right data at the right place at the right time and in the right format (Joshi 2000). It is introduced as one of the main requirement for successful implementation of CPFR in the literature (Joshi 2000). Information visibility can also improve both day-to-day and long-term collaboration between partners (Daugherty et al. 2006). Information visibility among trading partners will be achieved by accessing accurate data (e.g. forecasts and production capacity) by all supply chain members (Cassivi, 2006).

System compatibility has been identified as an effective factor in collaboration and information sharing schemes such as CPFR (Büyüközkan and Vardaloğlu, 2012; Fu et al. 2010). More system compatibility between partners will result in less development cost (Büyüközkan and Vardaloğlu, 2012).

Amalgamation can be defined as the action, process, or result of combining or uniting. Amalgamation capability of technology and culture is the ways in which technology has become woven into the fabric of culture so that it both shapes and is shaped by culture. According to Fu et al (2010) amalgamation capability of technology and culture has a significant impact on retailers' CPFR implementation.

Aviv (2007) and Fang and Meng (2010) identified an "internal service rate" as one of the key factors which affect the potential benefits and successful implementation of CPFR.

An organisations information system is critical to its CPFR implementation. A search conducted by Wang et al (2005) shows that information systems provide a platform through which a company can interact with its chain stores and suppliers in an efficient and timely manner. Stank et al (1999) state that "firms heavily engaged in CPFR also have information system capabilities that outdistance firms with lower levels of collaborative integration".

Internal alignment is the willingness of cross-functional departments to work together; to share ideas, information, and resources; and to develop and achieve collective goals (Ellinger et al. (2000). Previous literature on supply chain collaboration supports the idea that company's internal alignment significantly influences collaboration (Stank et al. 2001; Seifert, 2003).

In collaboration between a buyer and a supplier, the accuracy of the partner's information exchange is important for the both sides, but especially for the buyer. The lack of information accuracy may result in a delay in information sharing from partners until greater accuracy can be obtained (Whipple et al. 2002).

A common understanding between trading partners is essential for the implementation of CPFR. The willingness to collaborate with trading partners depends on the corporate culture and inculcated by top managers, in particular, being prepared to share data and risks. Also, it can be defined as the willingness to collaborate with partners in order to develop collaborative processes in forecasting and replenishment.

Information readiness indicates that the implementation executives must be assured that their trading partners act according to the defined information flow between them. The successful implementation of CPFR is dependent on data available to existing systems at each trading partner, and their ability to communicate with each other which are known as "information readiness". This ability is dependent on data representation standards and modes of data communication used by involved parties (Joshi, 2000). 


\begin{abstract}
Senior management support and commitment

Senior management support and commitment has been widely identified as a critical success factor in the collaboration literature (Ireland and Bruce, 2000; Frankel et al. 2002; Barrat, 2004; Cederlund et al. 2007; Attaran and Attaran, 2007). Strong senior management support is critical in organizational changes for a complex and long-term initiatives such as CPFR. Top management has significant ability to influence, support actual formation and implementation of CPFR initiatives across the enterprise. Barrat (2004) stressed its role to overcome functional friction among partners. Cultural fits and Partners' cultural capability and collaboration culture is known as a strategic challenge for supply collaborative culture chain alignment (Gattorna, 1998; Barrat, 2004). According to Wu et al (2009) the compatible culture

Organizational innovation

capability organization culture or cultural fits among partners has also positive effect on the information sharing.

Lin et al (2010, p.) defined innovation capability" as the ability of companies to assimilate and utilize external information for transfer into new knowledge". This definition of innovation capability is tied to the implementing of CPFR, since CPFR is established on information exchanging between firms. Organizational innovation capability is also identified by Fu et al (2010) as one of the major success factors in the CPFR implementation process. In a suppliermanufacturer relationship, an organizational innovation capability may originate and develop during the course of the relationship between partners (Panayides et al. 2009).

Flexible Organizational flexibility is defined as "the capacity to respond to environmental change" organizational (Palanisamy and Sushil, 2003). A flexible organizational structure is one in which workers can structure easily adapt to their customers' needs, efficiently complete their work and expedite decisionmaking when necessary. Flexible organizational structure is one of the critical success factors that can influence CPFR adoption for many companies (Wang et al. 2005; Attaran and Attaran, 2007).

Major change to Stank et al (1999) indicate that despite the fact that changes to operational processes, do not come operational easily or cheaply, high level of adopting CPFR are related to major changes to operational process.
\end{abstract}

process Information sharing security

In the CPFR implementation process, some partners are rightfully concerned about the idea of sharing strategic data such as financial reports, production planning and schedules and inventory levels and values. Information security triggers the fact that security protocols must be implemented to safeguard all trading partners from leaks of proprietary information.

Data
compatibility

across users

The role of data compatibility across users has been emphasised in the collaboration literature.

Electronic data interchange Partners will suffer from the issue of matching information into their internal enterprise resource planning (ERP) systems, if compatibility of information is not well controlled across partners (Whipple and Russell, 2007).

Electronic data interchange (EDI) is defined in Walton and Marucheck (1997) as "the transmission of standard business documents in a standard format between industrial trading partners from computer application to computer application”. The results of a study conducted by Fliedner (2003) show that EDI is one the key impact factors for adopting CPFR which has been echoed by Fu et al (2010). Hill and Scudder (2002) state that "the use of EDI has the natural effect of increasing interorganizational coordination activities, as well as increasing the integration that occurs between supply chain members".

Developing IT The availability of IT and technical infrastructure can simplify and enhance the speed and infrastructure flexibility of supply chain collaboration. Based on the degree of collaboration, various tools can support CPFR; from simple spreadsheet programmes to applications included in the Enterprise Resource Planning (ERP) software or specific CPFR solutions (ECR Europe, 2001).

System function According to Fu et al (2010), system function integrity is important to launch effective CPFR with integrity High level of trust trading partners.

The need for high level of trust between partners has been widely addressed in the collaboration literature (Fliedner, 2003; Wang and Archer, 2004; Lin et al. 2004; Wang et al. 2005; Attaran and Attaran, 2007; Ha et al. 2011). This factor indicates that a partner is willing to rely on exchange of information with other partner in whom it has trust. Lin et al (2004) indicate that high level of trust between partners is one of the most important CSFs of CPFR implementation. A lack of trust on the other hand will result in increasing the transaction cost as every transaction has to be scrutinized and verified by partners (Kwon and Suh, 2004).

Mutual agreed The importance of defining clear and mutual objectives at the outset of a collaborative agreement objectives has been highlighted in previous research (Frankel et al. 2002; Barrat, 2004; Fu et al. 2010), and conversely many CPFR projects will result in a failure if there are unclear objectives (Evrard- 


\begin{tabular}{ll}
\hline Clear & $\begin{array}{l}\text { Samuel, 2008). } \\
\text { A clear communication plan defines the objectives, measurable KPI's, target audiences, key } \\
\text { messanication } \\
\text { plan }\end{array}$ \\
$\begin{array}{l}\text { costs and important responsibilities and expectations. A clear communication plan helps to form an } \\
\text { effective communication between partners which is crucial for a successful collaboration (Fu et al. } \\
\text { 2010). }\end{array}$ \\
$\begin{array}{l}\text { Competition pressure has been recognised as an important driver for collaboration (e.g. Zhu et al. } \\
\text { pressure }\end{array}$ & $\begin{array}{l}\text { 2003; Fu et al. 2010). Competition pressure is defined in terms of its effects on a company's } \\
\text { incentives to collaborate with other firms in any kind of product and process innovations. }\end{array}$ \\
\hline
\end{tabular}

Table 2. CPFR implementation elements and sub elements

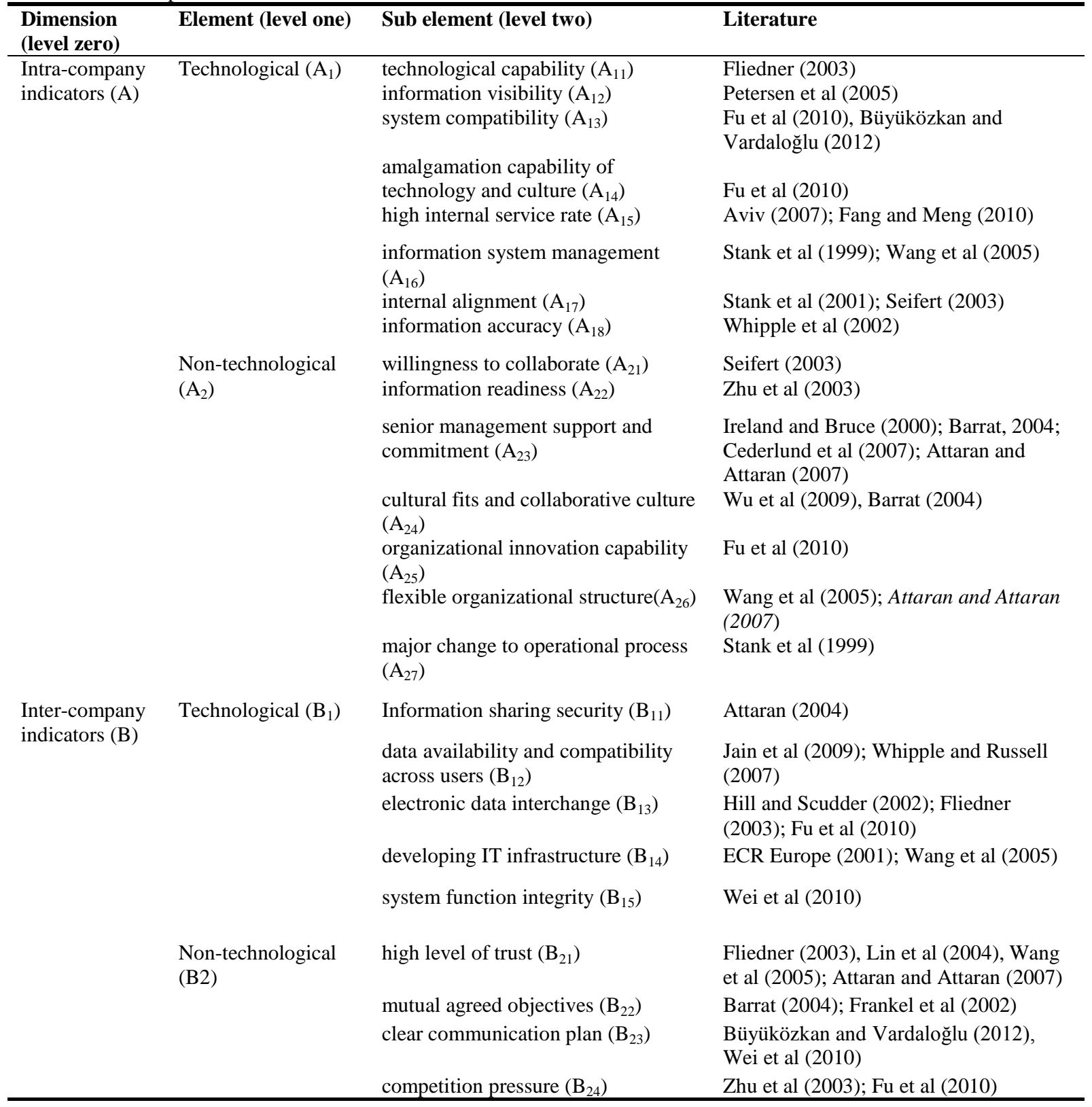


Table 3. The linguistic variables and their corresponding fuzzy numbers

\begin{tabular}{ll}
\hline Linguistic scale & Triangular fuzzy scale \\
\hline Just equal & $(1,1,1)$ \\
Equally important & $(2 / 3,1,3 / 2)$ \\
Weakly more important & $(1,3 / 2,2)$ \\
Strongly more important & $(3 / 2,2,5 / 2)$ \\
Very strongly more important & $(2,5 / 2,3)$ \\
Absolutely more important & $(5 / 2,3,7 / 2)$ \\
\hline
\end{tabular}

Table 4. Fuzzy evaluation matrix for $A_{1}$ sub elements

\begin{tabular}{lllllllll}
\hline & $\mathrm{A}_{11}$ & $\mathrm{~A}_{12}$ & $\mathrm{~A}_{13}$ & $\mathrm{~A}_{14}$ & $\mathrm{~A}_{15}$ & $\mathrm{~A}_{16}$ & $\mathrm{~A}_{17}$ & $\mathrm{~A}_{18}$ \\
\hline $\mathrm{A}_{11}$ & $(1,1,1)$ & $(2 / 3,1,3 / 2)$ & $(2 / 3,1,3 / 2)$ & $(1,3 / 2,2)$ & $(1,3 / 2,2)$ & $(3 / 2,2,5 / 2)$ & $(3 / 2,2,5 / 2)$ & $(2,5 / 2,3)$ \\
$\mathrm{A}_{12}$ & $(2 / 3,1,3 / 2)$ & $(1,1,1)$ & $(2 / 3,1,3 / 2)$ & $(2 / 3,1,3 / 2)$ & $(1,3 / 2,2)$ & $(1,3 / 2,2)$ & $(3 / 2,2,5 / 2)$ & $(3 / 2,2,5 / 2)$ \\
$\mathrm{A}_{13}$ & $(2 / 3,1,3 / 2)$ & $(2 / 3,1,3 / 2)$ & $(1,1,1)$ & $(2 / 3,1,3 / 2)$ & $(2 / 3,1,3 / 2)$ & $(1,3 / 2,2)$ & $(1,3 / 2,2)$ & $(3 / 2,2,5 / 2)$ \\
$\mathrm{A}_{14}$ & $(1 / 2,2 / 3,1)$ & $(2 / 3,1,3 / 2)$ & $(2 / 3,1,3 / 2)$ & $(1,1,1)$ & $(2 / 3,1,3 / 2)$ & $(2 / 3,1,3 / 2)$ & $(1,3 / 2,2)$ & $(1,3 / 2,2)$ \\
$\mathrm{A}_{15}$ & $(1 / 2,2 / 3,1)$ & $(1 / 2,2 / 3,1)$ & $(2 / 3,1,3 / 2)$ & $(2 / 3,1,3 / 2)$ & $(1,1,1)$ & $(2 / 3,1,3 / 2)$ & $(2 / 3,1,3 / 2)$ & $(1,3 / 2,2)$ \\
$\mathrm{A}_{16}$ & $(2 / 5,1 / 2,2 / 3)$ & $(1 / 2,2 / 3,1)$ & $(1 / 2,2 / 3,1)$ & $(2 / 3,1,3 / 2)$ & $(2 / 3,1,3 / 2)$ & $(1,1,1)$ & $(2 / 3,1,3 / 2)$ & $(2 / 3,1,1 / 2)$ \\
$\mathrm{A}_{17}$ & $(2 / 5,1 / 2,2 / 3)$ & $(2 / 5,1 / 2,2 / 3)$ & $(1 / 2,2 / 3,1)$ & $(1 / 2,2 / 3,1)$ & $(2 / 3,1,3 / 2)$ & $(2 / 3,1,3 / 2)$ & $(1,1,1)$ & $(2 / 3,1,1 / 2)$ \\
$\mathrm{A}_{18}$ & $(1 / 3,2 / 5,1 / 2)$ & $(2 / 5,1 / 2,2 / 3)$ & $(2 / 5,1 / 2,2 / 3)$ & $(1 / 2,2 / 3,1)$ & $(1 / 2,2 / 3,1)$ & $(2 / 3,1,3 / 2)$ & $(2 / 3,1,3 / 2)$ & $(1,1,1)$ \\
\hline
\end{tabular}

Table5. Fuzzy evaluation matrix for $A_{2}$ sub elements

\begin{tabular}{llllllll}
\hline & $\mathrm{A}_{21}$ & $\mathrm{~A}_{22}$ & $\mathrm{~A}_{23}$ & $\mathrm{~A}_{24}$ & $\mathrm{~A}_{25}$ & $\mathrm{~A}_{26}$ & $\mathrm{~A}_{27}$ \\
\hline $\mathrm{A}_{21}$ & $(1,1,1)$ & $(2 / 3,1,3 / 2)$ & $(2 / 3,1,3 / 2)$ & $(1,3 / 2,2)$ & $(1,3 / 2,2)$ & $(3 / 2,2,5 / 2)$ & $(3 / 2,2,5 / 2)$ \\
$\mathrm{A}_{22}$ & $(2 / 3,1,3 / 2)$ & $(1,1,1)$ & $(2 / 3,1,3 / 2)$ & $(2 / 3,1,3 / 2)$ & $(1,3 / 2,2)$ & $(1,3 / 2,2)$ & $(3 / 2,2,5 / 2)$ \\
$\mathrm{A}_{23}$ & $(2 / 3,1,3 / 2)$ & $(2 / 3,1,3 / 2)$ & $(1,1,1)$ & $(2 / 3,1,3 / 2)$ & $(2 / 3,1,3 / 2)$ & $(1,3 / 2,2)$ & $(1,3 / 2,2)$ \\
$\mathrm{A}_{24}$ & $(1 / 2,2 / 3,1)$ & $(2 / 3,1,3 / 2)$ & $(2 / 3,1,3 / 2)$ & $(1,1,1)$ & $(2 / 3,1,3 / 2)$ & $(2 / 3,1,3 / 2)$ & $(1,3 / 2,2)$ \\
$\mathrm{A}_{25}$ & $(1 / 2,2 / 3,1)$ & $(1 / 2,2 / 3,1)$ & $(2 / 3,1,3 / 2)$ & $(2 / 3,1,3 / 2)$ & $(1,1,1)$ & $(2 / 3,1,3 / 2)$ & $(2 / 3,1,3 / 2)$ \\
$\mathrm{A}_{26}$ & $(2 / 5,1 / 2,2 / 3)$ & $(1 / 2,2 / 3,1)$ & $(1 / 2,2 / 3,1)$ & $(2 / 3,1,3 / 2)$ & $(2 / 3,1,3 / 2)$ & $(1,1,1)$ & $(2 / 3,1,3 / 2)$ \\
$\mathrm{A}_{27}$ & $(2 / 5,1 / 2,2 / 3)$ & $(2 / 5,1 / 2,2 / 3)$ & $(1 / 2,2 / 3,1)$ & $(1 / 2,2 / 3,1)$ & $(2 / 3,1,3 / 2)$ & $(2 / 3,1,3 / 2)$ & $(1,1,1)$ \\
\hline
\end{tabular}

Table6. Fuzzy evaluation matrix for $\mathrm{B}_{1}$ sub elements

\begin{tabular}{llllll}
\hline & $\mathrm{B}_{11}$ & $\mathrm{~B}_{12}$ & $\mathrm{~B}_{13}$ & $\mathrm{~B}_{14}$ & $\mathrm{~B}_{15}$ \\
\hline $\mathrm{B}_{11}$ & $(1,1,1)$ & $(2 / 3,1,3 / 2)$ & $(1,3 / 2,2)$ & $(3 / 2,2,5 / 2)$ & $(2,5 / 2,6 / 2)$ \\
$\mathrm{B}_{12}$ & $(2 / 3,1,3 / 2)$ & $(1,1,1)$ & $(2 / 3,1,3 / 2)$ & $(1,3 / 2,2)$ & $(3 / 2,2,5 / 2)$ \\
$\mathrm{B}_{13}$ & $(1 / 2,2 / 3,1)$ & $(2 / 3,1,3 / 2)$ & $(1,1,1)$ & $(2 / 3,1,3 / 2)$ & $(1,3 / 2,2)$ \\
$\mathrm{B}_{14}$ & $(2 / 5,1 / 2,2 / 3)$ & $(1 / 2,2 / 3,1)$ & $(2 / 3,1,3 / 2)$ & $(1,1,1)$ & $(2 / 3,1,3 / 2)$ \\
$\mathrm{B}_{15}$ & $(1 / 3,2 / 5,1 / 2)$ & $(2 / 5,1 / 2,2 / 3)$ & $(1 / 2,2 / 3,1)$ & $(2 / 3,1,3 / 2)$ & $(1,1,1)$ \\
\hline
\end{tabular}

Table7. Fuzzy evaluation matrix for $\mathrm{B}_{2}$ sub elements

\begin{tabular}{lllll}
\hline & $\mathrm{B}_{21}$ & $\mathrm{~B}_{22}$ & $\mathrm{~B}_{23}$ & $\mathrm{~B}_{24}$ \\
\hline $\mathrm{B}_{21}$ & $(1,1,1)$ & $(2 / 3,1,3 / 2)$ & $(1,3 / 2,2)$ & $(3 / 2,2,5 / 2)$ \\
$\mathrm{B}_{22}$ & $(2 / 3,1,3 / 2)$ & $(1,1,1)$ & $(2 / 3,1,3 / 2)$ & $(1,3 / 2,2)$ \\
$\mathrm{B}_{23}$ & $(1 / 2,2 / 3,1)$ & $(2 / 3,1,3 / 2)$ & $(1,1,1)$ & $(2 / 3,1,3 / 2)$ \\
$\mathrm{B}_{24}$ & $(2 / 5,1 / 2,2 / 3)$ & $(1 / 2,2 / 3,1)$ & $(2 / 3,1,3 / 2)$ & $(1,1,1)$ \\
\hline
\end{tabular}


Table8. Overall FEAHP weights

\begin{tabular}{|c|c|c|c|c|c|c|}
\hline Dimension & Weight & Element & Weight & $\begin{array}{l}\text { Sub } \\
\text { element }\end{array}$ & Weight & $\begin{array}{l}\text { Global } \\
\text { weight }\end{array}$ \\
\hline \multirow[t]{15}{*}{$\mathrm{A}$} & \multirow[t]{15}{*}{0.5} & \multirow[t]{8}{*}{$\mathrm{A}_{1}$} & \multirow[t]{8}{*}{0.39} & $\mathrm{~A}_{11}$ & 0.100 & 0.0195 \\
\hline & & & & $\mathrm{A}_{12}$ & 0.140 & 0.0273 \\
\hline & & & & $\mathrm{A}_{13}$ & 0.075 & 0.0146 \\
\hline & & & & $\mathrm{A}_{14}$ & 0.189 & 0.0369 \\
\hline & & & & $\mathrm{A}_{15}$ & 0.060 & 0.0117 \\
\hline & & & & $\mathrm{A}_{16}$ & 0.165 & 0.0322 \\
\hline & & & & $\mathrm{A}_{17}$ & 0.122 & 0.0238 \\
\hline & & & & $\mathrm{A}_{18}$ & 0.149 & 0.0291 \\
\hline & & \multirow[t]{7}{*}{$\mathrm{A} 2$} & \multirow[t]{7}{*}{0.61} & $\mathrm{~A}_{21}$ & 0.159 & 0.0485 \\
\hline & & & & $\mathrm{A}_{22}$ & 0.192 & 0.0583 \\
\hline & & & & $\mathrm{A}_{23}$ & 0.176 & 0.0537 \\
\hline & & & & $\mathrm{A}_{24}$ & 0.111 & 0.0339 \\
\hline & & & & $A_{25}$ & 0.143 & 0.0436 \\
\hline & & & & $\mathrm{A}_{26}$ & 0.095 & 0.0290 \\
\hline & & & & $\mathrm{A}_{27}$ & 0.125 & 0.0381 \\
\hline \multirow[t]{9}{*}{ B } & \multirow[t]{9}{*}{0.5} & \multirow[t]{5}{*}{$\mathrm{B}_{1}$} & \multirow[t]{5}{*}{0.39} & $\mathrm{~B}_{11}$ & 0.264 & 0.0515 \\
\hline & & & & $\mathrm{B}_{12}$ & 0.134 & 0.0261 \\
\hline & & & & $\mathrm{B}_{13}$ & 0.199 & 0.0388 \\
\hline & & & & $\mathrm{B}_{14}$ & 0.326 & 0.0636 \\
\hline & & & & $\mathrm{B}_{15}$ & 0.077 & 0.0150 \\
\hline & & \multirow[t]{4}{*}{$\mathrm{B}_{2}$} & \multirow[t]{4}{*}{0.61} & $\mathrm{~B}_{21}$ & 0.218 & 0.0665 \\
\hline & & & & $\mathrm{B}_{22}$ & 0.337 & 0.1028 \\
\hline & & & & $\mathrm{B}_{23}$ & 0.278 & 0.0848 \\
\hline & & & & $\mathrm{B}_{24}$ & 0.167 & 0.0509 \\
\hline
\end{tabular}

Table9. Ranking of CPFR implementation enablers in the automotive spare parts industry (group 1)

\begin{tabular}{lcc}
\hline Sub element & Weights & Ranking \\
\hline Mutual agreed objectives & 0.1028 & 1 \\
Clear communication plan & 0.0848 & 2 \\
High level of trust & 0.0665 & 3 \\
Developing IT infrastructure & 0.0636 & 4 \\
Information readiness & 0.0583 & 5 \\
Senior management support and & & \\
commitment & 0.0537 & 6 \\
Information security & 0.0515 & 7 \\
Competition pressure & 0.0509 & 8 \\
Willingness to collaborate & 0.0485 & 9 \\
Organizational innovation capability & 0.0436 & 10 \\
Electronic data interchange & 0.0388 & 11
\end{tabular}


major change to operational process

Amalgamation capability of technology

and culture

Information accuracy

Flexible organizational structure
0.0381

$0.0369 \quad 13$

$0.0291 \quad 14$

0.0290

0.7983

Table10. Ranking of CPFR implementation enablers in the automotive industry (group 2)

\begin{tabular}{lccccccccc}
\hline Enablers & $\mathbf{E}_{\mathbf{1}}$ & $\mathbf{E}_{\mathbf{2}}$ & $\mathbf{E}_{\mathbf{3}}$ & $\mathbf{E}_{\mathbf{4}}$ & $\mathbf{E}_{\mathbf{5}}$ & $\mathbf{E}_{\mathbf{6}}$ & $\mathbf{E}_{\mathbf{7}}$ & Votes & Ranking \\
\hline Senior management support & 5 & 4 & 5 & 3 & 4 & 5 & 4 & 30 & $\mathbf{2}$ \\
Competition pressure & 5 & 5 & 5 & 4 & 5 & 4 & 3 & 31 & $\mathbf{1}$ \\
Clear communication plan & 5 & 5 & 3 & 5 & 4 & 3 & 4 & 29 & $\mathbf{3}$ \\
Mutual agreed objectives & 4 & 3 & 4 & 3 & 4 & 5 & 4 & 27 & $\mathbf{5}$ \\
Willingness to collaborate & 3 & 3 & 5 & 4 & 5 & 4 & 3 & 27 & $\mathbf{5}$ \\
Information accuracy & 4 & 4 & 4 & 3 & 4 & 5 & 4 & 28 & $\mathbf{4}$ \\
High level of trust & 5 & 4 & 5 & 5 & 3 & 3 & 5 & 30 & $\mathbf{2}$ \\
Information security & 4 & 5 & 3 & 3 & 5 & 5 & 4 & 29 & $\mathbf{3}$ \\
Internal alignment & 3 & 4 & 4 & 3 & 3 & 3 & 3 & 23 & $\mathbf{7}$ \\
Information readiness & 3 & 3 & 4 & 5 & 3 & 4 & 4 & 26 & $\mathbf{6}$ \\
Perceived benefit & 4 & 4 & 3 & 2 & 3 & 3 & 2 & 21 & $\mathbf{9}$ \\
Developing IT infrastructure & 4 & 4 & 3 & 3 & 5 & 4 & 3 & 26 & $\mathbf{6}$ \\
Flexible organization & 3 & 3 & 2 & 4 & 4 & 3 & 2 & 21 & $\mathbf{9}$ \\
cultural fits and collaborative & 2 & 3 & 4 & 3 & 3 & 4 & 2 & 21 & $\mathbf{9}$ \\
culture & 3 & 4 & 3 & 3 & 4 & 2 & 3 & 22 & $\mathbf{8}$ \\
Technological capability & & & & & & & &
\end{tabular}

Table 11. Structural self-interaction matrix (SSIM)

\begin{tabular}{lccccccccc}
\hline Enablers & $\mathbf{1 0}$ & $\mathbf{9}$ & $\mathbf{8}$ & $\mathbf{7}$ & $\mathbf{6}$ & $\mathbf{5}$ & $\mathbf{4}$ & $\mathbf{3}$ & $\mathbf{2}$ \\
\hline 1. Information readiness & $\mathrm{A}$ & $\mathrm{A}$ & $\mathrm{O}$ & $\mathrm{X}$ & $\mathrm{A}$ & $\mathrm{A}$ & $\mathrm{A}$ & $\mathrm{A}$ & $\mathrm{A}$ \\
2. Developing IT infrastructure & $\mathrm{A}$ & $\mathrm{A}$ & $\mathrm{V}$ & $\mathrm{X}$ & $\mathrm{A}$ & $\mathrm{A}$ & $\mathrm{A}$ & $\mathrm{X}$ & \\
3. Information security & $\mathrm{A}$ & $\mathrm{A}$ & $\mathrm{V}$ & $\mathrm{V}$ & $\mathrm{A}$ & $\mathrm{A}$ & $\mathrm{A}$ & & \\
4. Mutual agreed objectives & $\mathrm{A}$ & $\mathrm{A}$ & $\mathrm{V}$ & $\mathrm{V}$ & $\mathrm{A}$ & $\mathrm{A}$ & & & \\
5. Competition pressure & $\mathrm{V}$ & $\mathrm{V}$ & $\mathrm{V}$ & $\mathrm{V}$ & $\mathrm{V}$ & & & & \\
6. Clear communication plan & $\mathrm{X}$ & $\mathrm{X}$ & $\mathrm{V}$ & $\mathrm{V}$ & & & & & \\
7. High level of trust & $\mathrm{A}$ & $\mathrm{A}$ & $\mathrm{X}$ & & & & & & \\
8. Information accuracy & $\mathrm{A}$ & $\mathrm{A}$ & & & & & & & \\
9. Senior management support & $\mathrm{X}$ & & & & & & & & \\
and commitment & & & & & & & & &
\end{tabular}

10. Willingness to collaborate 
Table 12. Final Reachability Matrix - CPFR Implementation Enablers in the automotive sector

\begin{tabular}{cccccccccccccc}
\hline Enablers & $\mathbf{1}$ & $\mathbf{2}$ & $\mathbf{3}$ & $\mathbf{4}$ & $\mathbf{5}$ & $\mathbf{6}$ & $\mathbf{7}$ & $\mathbf{8}$ & $\mathbf{9}$ & $\mathbf{1 0}$ & $\begin{array}{c}\text { Driving } \\
\text { power }\end{array}$ & Ranks \\
\hline $\mathbf{1}$ & 1 & 0 & 0 & 0 & 0 & 0 & 1 & 0 & 0 & 0 & 2 & $\mathbf{6}$ \\
$\mathbf{2}$ & 1 & 1 & 1 & 0 & 0 & 0 & 1 & 1 & 0 & 0 & 5 & $\mathbf{4}$ \\
$\mathbf{4}$ & 1 & 1 & 1 & 0 & 0 & 0 & 1 & 1 & 0 & 0 & 5 & $\mathbf{4}$ \\
$\mathbf{5}$ & 1 & 1 & 1 & 1 & 0 & 0 & 1 & 1 & 0 & 0 & 6 & $\mathbf{3}$ \\
$\mathbf{6}$ & 1 & 1 & 1 & 1 & 1 & 1 & 1 & 1 & 1 & 1 & 10 & $\mathbf{1}$ \\
$\mathbf{7}$ & 1 & 1 & 1 & 1 & 0 & 1 & 1 & 1 & 1 & 1 & 9 & $\mathbf{2}$ \\
$\mathbf{8}$ & 1 & 0 & 0 & 0 & 0 & 0 & 1 & 1 & 0 & 0 & 3 & $\mathbf{5}$ \\
$\mathbf{9}$ & 0 & 0 & 0 & 0 & 0 & 0 & 1 & 1 & 0 & 0 & 2 & $\mathbf{6}$ \\
$\mathbf{1 0}$ & 1 & 1 & 1 & 1 & 0 & 1 & 1 & 1 & 1 & 1 & 9 & $\mathbf{2}$ \\
Dependence & 9 & 8 & 7 & 5 & 1 & 4 & 10 & 9 & 4 & 4 & $\mathbf{6 0}$ & $\mathbf{2}$ \\
Ranks & $\mathbf{2}$ & $\mathbf{3}$ & $\mathbf{4}$ & $\mathbf{5}$ & $\mathbf{7}$ & $\mathbf{6}$ & $\mathbf{1}$ & $\mathbf{2}$ & $\mathbf{6}$ & $\mathbf{6}$ & & \\
\hline
\end{tabular}

Table 13. Iteration 1

\begin{tabular}{ccccc}
\hline Enablers & Reachability Set & Antecedent Set & Intersection & Level \\
\hline 1 & 1,7 & $1,2,3,4,5,6,7,9,10$ & 1,7 & I \\
2 & $1,2,3,7,8$ & $2,3,4,5,6,9,10$ & 2,3 & \\
3 & $1,2,3,7,8$ & $2,3,4,5,6,9,10$ & 2,3 & \\
4 & $1,2,3,4,7,8$ & $4,5,6,9,10$ & 4 & \\
5 & $1,2,3,4,5,6,7,8,9,10$ & 5 & 5 & \\
6 & $1,2,3,4,6,7,8,9,10$ & $5,6,9,10$ & $6,9,10$ & \\
7 & $1,7,8$ & $1,2,3,4,5,6,7,8,9,10$ & $1,7,8$ & I \\
8 & 7,8 & $2,3,4,5,6,7,8,9,10$ & 7,8 & I \\
9 & $1,2,3,4,6,7,8,9,10$ & $5,6,9,10$ & $6,9,10$ & \\
10 & $1,2,3,4,6,7,8,9,10$ & $5,6,9,10$ & $6,9,10$ & \\
\hline
\end{tabular}

Table 14. Iteration 2

\begin{tabular}{lllll}
\hline Enablers & Reachability Set & Antecedent Set & Intersection & Level \\
\hline
\end{tabular}




\begin{tabular}{ccccc}
\hline 2 & 2,3 & $2,3,4,5,6,9,10$ & 2,3 & II \\
3 & 2,3 & $2,3,4,5,6,9,10$ & 2,3 & II \\
4 & $2,3,4$ & $4,5,6,9,10$ & 4 & \\
5 & $2,3,4,5,6,9,10$ & 5 & 5 & \\
6 & $2,3,4,6,9,10$ & $5,6,9,10$ & $6,9,10$ & \\
9 & $2,3,4,6,9,10$ & $5,6,9,10$ & $6,9,10$ & \\
10 & $2,3,4,6,9,10$ & $5,6,9,10$ & $6,9,10$ & \\
\hline
\end{tabular}

Table 15. Iteration 3

\begin{tabular}{ccccc}
\hline Enablers & Reachability Set & Antecedent Set & Intersection & Level \\
\hline 4 & 4 & $4,5,6,9,10$ & 4 & III \\
5 & $4,5,6,9,10$ & 5 & 5 & \\
6 & $4,6,9,10$ & $5,6,9,10$ & $6,9,10$ & \\
9 & $4,6,9,10$ & $5,6,9,10$ & $6,9,10$ & \\
10 & $4,6,9,10$ & $5,6,9,10$ & $6,9,10$ & \\
\hline
\end{tabular}

Table 16. Iteration 4

\begin{tabular}{ccccc}
\hline Enablers & Reachability Set & Antecedent Set & Intersection & Level \\
\hline 5 & $5,6,9,10$ & 5 & 5 & \\
6 & $6,9,10$ & $5,6,9,10$ & $6,9,10$ & IV \\
9 & $6,9,10$ & $5,6,9,10$ & $6,9,10$ & IV \\
10 & $6,9,10$ & $5,6,9,10$ & $6,9,10$ & IV \\
\hline
\end{tabular}

Table 17. Iteration 5

\begin{tabular}{ccccc}
\hline Enablers & Reachability Set & Antecedent Set & Intersection & Level \\
\hline 5 & 5 & 5 & 5 & V \\
\hline
\end{tabular}

Appendix - Abbreviations used in the paper

CPFR Collaborative planning, forecasting and replenishment

ISM Interpretive Structural Modeling 


\begin{tabular}{ll}
\hline FEAHP & Fuzzy Extended Analytical Hierarchy Process \\
AHP & Analytic Hierarchy Process \\
CSFs & Critical Success Factors \\
VMI & Vendor Managed Inventory \\
ECR & Efficient Customer Response \\
ERP & Enterprise Resource Planning \\
EDI & Electronic Data Interchange \\
ANP & Analytical Network Process \\
MCGDM & Multi-Criteria Group Decision Making \\
MCDM & Multi Criteria Decision-Making \\
SSIM & Structural Self Interaction Matrix \\
NGT & Nominal Group Technique \\
MICMAC & Matrice d'Impacts croises-multiplication appliqúe an classment \\
KPIs & Key Performance Indicators \\
SEM & Structural Equation Modelling \\
\hline
\end{tabular}

